\title{
Lo sagrado bajo el prisma de la museología
}

\section{François Mairesse}

\section{OpenEdition}

\section{Journals}

\section{Edición electrónica}

URL: http://journals.openedition.org/iss/1301

DOI: 10.4000/iss.1301

ISSN: 2306-4161

\section{Editor}

ICOM - International Council of Museums

\section{Edición impresa}

Fecha de publicación: 12 octubre 2019

Paginación: 31-38

ISBN: 978-92-9012-467-2

ISSN: 2309-1290

\section{Referencia electrónica}

François Mairesse, "Lo sagrado bajo el prisma de la museología », ICOFOM Study Series [En línea], 47(1-2) | 2019, Publicado el 12 octubre 2019, consultado el 24 septiembre 2020. URL : http:// journals.openedition.org/iss/1301; DOI : https://doi.org/10.4000/iss.1301 


\section{Lo sagrado bajo
el prisma de la museología}

\section{François Mairesse Sorbonne nouvelle-Paris3, CERLIS, CNRS, ICCA}

Los artículos reunidos en este número, que tratan sobre los vínculos entre los museos, la museología y lo sagrado, se nutrieron en su mayor parte de las discusiones del $4 \mathrm{I}^{\circ}$ simposio organizado por el ICOFOM sobre este tema en Teherán, del I5 al ig de octubre de 2018 (Mairesse, 20I8). Estas contribuciones buscan continuar las reflexiones y discusiones, a menudo apasionadas, iniciadas durante estas reuniones.

No hay duda de que el tema de lo sagrado es de una importancia capital para el mundo de los museos, tanto por los objetos que los museos presentan como por la esencia misma de la institución y el rol a veces ambiguo que este último juega al respecto. El museo puede ser a la vez acusado de sacralizar objetos seculares y al mismo tiempo de profanar objetos sagrados. Desde un punto de vista etimológico, el término incluye la idea de separación (Texier, 1990): el espacio de lo sagrado está vinculado a esta experiencia particular del encuentro con lo divino (Hierofanía). Temor y Pavor (Otto, 1969), experiencia de la realidad o de aquello que es lo más real en este mundo (Eliade, 1965). Si definimos la museología, tal como Stránský lo sugirió en la década de I980, como el estudio de una relación específica del hombre con la realidad (Gregorová, I980), ¿de qué la realidad estamos hablando? A primera vista, el contexto en el que Stránský escribe nos permite tener una cierta idea de su concepción de la realidad, proveniente de la Ilustración y del pensamiento marxista. Cuando el museólogo de Brno considera esta perspectiva específica, es desde una visión basada en la constitución activa de colecciones materiales en relación a las disciplinas clásicas, la arqueología, la etnografía, las ciencias naturales o la historia de arte (Mairesse, 2019). El rol del museo, de acuerdo con esta visión de las cosas, se inscribe en un abordaje científico (y accesoriamente estético) del mundo. Lo sagrado aparece esencialmente como un objeto de estudio 
etnográfico o histórico desde una perspectiva en gran medida agnóstica o atea: cualquier otro tipo de experiencia distinta a la propuesta por la ciencia o la estética parece un poco absurda, a menos que sea a su vez observada y analizada de la misma manera.

Sin embargo, el mundo museal, al procurar deshacerse de la omnipresente dimensión religiosa del patrimonio a su cargo, parece que solo ha movido el cursor. Su modo de operación comporta también, a través de sus prácticas y sus espacios, una dimensión que se aproxima a aquella que se observa en el seno de otros lugares sagrados: arquitectura, modos de visita (Duncan y Wallach, 1978), posicionamiento de los conservadores-iniciados en comparación con los seculares, etc. (Mairesse, 20r4). Paralelamente a estas evoluciones que pueden seguirse de acuerdo con la historia museal, instituciones de lo sagrado (templos, iglesias, lugares de peregrinación) han igualmente desarrollado dispositivos de exhibición cuyo utilización parece sorprendentemente similar al de los museos clásicos: visitas, venta de catálogos o de souvenirs, etc. Al mismo tiempo, muchos lugares anteriormente consagrados (templos, iglesias, etc.) se han convertido en museos y sitios patrimoniales.

¿Qué se puede decir acerca de este cercano entrelazamiento entre dos mundos que a priori parecen completamente separados, pero cuyo análisis revela prácticas que a veces son sorprendentemente similares? Las conclusiones del Simposio de Teherán, así como los artículos de esta publicación que permiten continuar la discusión, no tienen por objetivo circunscribir el tema, sino que nos permiten presentar algunas perspectivas de investigación a fin de comprender mejor la interrelación entre los dos dominios.

\section{La etapa sagrada}

Un primer elemento, que ha surgido directamente de los debates, se refiere a la naturaleza de lo sagrado, su presencia a través de ciertos objetos y la jerarquía implícita resultante de ello. Una perspectiva bastante general ampliamente mencionada durante el coloquio, apunta a reconocer lo sagrado en una gran cantidad de lugares u objetos: paisajes, bosques, cursos de agua, montañas, objetos de culto, etc. Según esa visión de las cosas, lo sagrado aparece inevitablemente tanto en el museo como en la naturaleza a lo largo de un sendero, Sin embargo, de la misma manera que las otras jerarquías (estética, valor financiero), ciertos lugares o ciertos objetos, como la Kaaba o el Santo Sudario de Turín, parecen más sagrados que otros. Si podemos considerar las obras de arte o los testimonios históricos desde el punto de vista de cierta sacralidad, los objetos de culto presentan en su mayor parte un «nivel de sacralidad» diferente del que podríamos encontrar frente a la Piedra Roseta o incluso la Mona Lisa, por nombrar solo dos ejemplos famosos. Este estado de cosas puede que aunque puede parecer trivial nos permite, sin embargo, observar que los objetos considerados actualmente como los más sagrados (todas las sociedades combinadas) no se conservan en los museos (al menos en los museos seculares, pues algunos templos también han creado espacios musealizados). Si se pudiera 
observar de cerca la momia de Tutankamón, ciertamente de un nivel muy alto de santidad durante la época faraónica, los objetos o los lugares más sagrados de las grandes religiones actuales (reliquias, espacios de lo sagrado) no figuran en los museos pero permanecen vinculados al culto. Lo sagrado aparece nuevamente, desde esta perspectiva, como retirado de los lugares seculares, e incluso si el museo funciona en gran medida como un espacio por fuera de lo cotidiano, no parece ofrecer características similares a las que prevalecen en los lugares directamente concebidos a partir de su relación tradicional con lo sagrado. El museo busca musealizar el mundo a través de sus objetos, pero algunos de ellos todavía parecen tener la fuerza suficiente para resistirlo. Si continuamos este razonamiento, debe tenerse en cuenta que la fuerza de las poblaciones o sociedades asociadas con ciertos objetos es lo que determina su lugar (o su ausencia) en el seno del museo: cuanto más un culto debilita (o está vinculado a un poder débil en el plano político o militar), más tiene la posibilidad de ser musealizado. Esto puede observarse particularmente para la herencia de sociedades desaparecidas, dominadas o colonizadas. Por otro lado, las solicitudes de restitución dirigidas (y obtenidas) en los últimos años por los pueblos indígenas y las sociedades anteriormente colonizadas, atestiguan tanto las nuevas relaciones de poder geopolítico como el resurgimiento de la vitalidad de ciertas creencias ancestrales.

Un segundo principio de nuestra relación con lo sagrado está constituido por el vínculo entre el lugar (o el objeto) y el intercesor, que es quien reconoce o hace brotar lo sagrado. Para que lo sagrado se manifieste, hace falta un hechicero, un eclesiástico o al menos un actor reconocido por la comunidad y facultado para reunir los dos mundos (el profano y el sacro), que da testimonio de su presencia o lo hace aparecer a través de un ritual. La práctica museal, desde esta perspectiva, difiere ampliamente de aquella que se encuentra en los lugares de culto. Es cierto que el conservador (o el curador, o el mediador, de acuerdo con los principios de la jerarquía museal) da fe, por así decirlo, de la musealidad de un objeto, es decir, de lo que condicionó su selección, su tesaurización y su presentación: una silla musealizada pierde su estatus de silla en el mundo profano (sujeto a su valor de uso) para ser presentada de acuerdo con su valor de documentación y representación de lo real (su musealidad). Tanto los curadores como el clero se consideran facultados para reconocer un cierto nivel de realidad más allá del mundo secular. Por otro lado, el poder del curador se detiene donde realmente comienza el del sacerdote o el chamán, que puede traer lo sagrado o entrar en comunión con la trascendencia. El plan de la musealidad, desde esta perspectiva, parece estar fuera de sintonía con aquello a lo que lo sagrado conduce, el rol del museo y el de la iglesia no pueden conducir, a pesar de algunas similitudes en su enfoque, a las mismas perspectivas sobre lo Real.

$\mathrm{Si}$, como ya ha sido sugerido, es posible mencionar las muchas similitudes entre museos y templos (Mairesse, 20I4), también es posible tratar de comprender de qué manera los dispositivos de selección, documentación y presentación 
utilizados por ambas instituciones difieren. La estructura de presentación de lo sagrado, en este sentido, constituye un tercer eje de reflexión. Los museos y los templos (iglesias, mezquitas, etc.) muestran objetos -reliquias, objetos de culto, testimonios históricos- de acuerdo con dispositivos de presentación e interpretación a veces similares. También los almacenan de acuerdo con métodos relativamente idénticos (para garantizar su mejor conservación). Los modos de valoración de estos objetos, sin embargo, varían considerablemente entre las dos instituciones. La cuestión de la luminosidad de los espacios parece más bien globalmente separar los dos mundos. La iluminación museal, aunque puede restringirse (por razones de conservación preventiva), tiene como objetivo proporcionar al público las condiciones óptimas para la legibilidad de los objetos. Es este mismo principio el que guía la presentación de la musealia: ofrecer para ser visto y, por lo tanto, presentar los objetos para que puedan ser percibidos bajo una mejor luz y poder ser observados desde todos los ángulos. Los principios por los cuales se muestran los objetos en los templos o lugares de culto parecen estar basados en la lógica opuesta, según la cual la oscuridad o la penumbra a veces revela mejor la dimensión sagrada de los objetos. Los registros de las exhibiciones de lo sagrado parecen usar tanto, y a veces más, la sombra como la luz, así el paso a lo luminoso aparece como una secuencia mucho más limitada (como la apertura de un retablo) que la que observamos en los museos. El museo no es totalmente refractario a la oscuridad (que utiliza en sus reservas), pero cuando recurre a su utilización en sus exhibiciones, lo hace para mejor resaltar objetos, o (más recientemente) para evocar el carácter sagrado de ciertos objetos específicos. Finalmente, la elección de los principios de mostración refleja, en ambos casos, jerarquías de valores muy diferentes. $\mathrm{Si}$, para una tradición religiosa específica, los criterios para la exhibición de objetos están vinculados a una jerarquía inherente al culto que le es propia, el museo se basa en criterios tanto estandarizados como igualitarios (los cultos y las religiones se examinan a la luz del conocimiento científico y bajo esta perspectiva todos los cultos son iguales) y jerarquizados según los criterios patrimoniales (el orden de presentación de los objetos está relacionado con su valor estético, histórico o su aporte científico).

\section{La etapa del museo}

La museología, en el sentido en que Stránský la entendió, presupone la existencia de instituciones anteriores a los museos, aquellas que conocemos como tesauros, gabinetes, etc. (Mairesse, 2019). Los ejemplos dados por este último no incluyen lugares de culto, el museólogo de Brno no fue claro a este respecto. Durante siglos, sin embargo, ha habido colecciones en estos ámbitos (obras de arte, pero también naturalia) más o menos relacionadas con el culto, que Lugli (1998) presenta como muy asociados con el origen de los gabinetes de curiosidades. Desde un punto de vista histórico, por lo tanto, la evolución conjunta de los museos (o de sus predecesores) y de los sitios de culto, merece ser tenida en cuenta. Un rápido vistazo a la evolución de las dos instituciones en Occidente hace posible conjeturar la hipótesis que la evolución de una ha 
ocurrido en paralelo con el declive de la otra: el número de museos creados parece aumentar proporcionalmente con el número de iglesias desafectadas (Mairesse, 20I4).

El «deslizamiento» de objetos o espacios sagrados hacia lo profano (su secularización), que se puede observar a lo largo de la historia de la humanidad: colapsos de civilizaciones, como Egipto, Roma, etc. pero también las luchas y cismas, como las olas de iconoclasia durante la Reforma en Occidente, han resultado en la desaparición (u ocultamiento) de estos objetos o de estos lugares específicos. El desarrollo del fenómeno museal desde el Renacimiento, da lugar a la creación de terceros lugares, a medio camino entre el mundo de lo sagrado y el de residuos inútiles, futuro reino del arqueólogo (Mensch, I992). Al flujo natural de objetos entre los dos mundos -espacio de lo sagrado, espacio de lo profano y luego de residuos- se une a nuevas circulaciones, incluidos los museos, pero también a nuevos encuentros, sin precedente, entre los objetos de estos diferentes registros. Considerados durante mucho tiempo como testimonios únicos de cierto tipo de realidad, de repente se presentan como tantos testimonios, no de una realidad, sino de una civilización y su forma de concebir lo sagrado. El punto de vista relativista del museo, al presentar, suspendidos en el mismo espacio, artefactos de todas las religiones y creencias, tiene el mérito de presentar un discurso idéntico, construido sobre un doble registro científico y estético, pero en detrimento de formas de explicación relacionadas con los registros de lo sagrado propio de cada culto, que de alguna manera se debilitan, condujeron a cohabitar conjuntos a partir de un discurso unificador, pero reductor. Sin embargo, estos objetos al ser integrados por los museos también han permitido la preservación (en un estado fantasmal o más o menos comatoso) de elementos, a menudo orgánicos y perecederos, que de otro modo habrían corrido el riesgo de desaparecer.

Este es un modo de apropiación de lo real que será progresivamente desafiado poco después de la Segunda Guerra Mundial, de acuerdo con las solicitudes de restitución y, más recientemente, con un análisis más crítico de la lógica colonial y depredadora del museo. El «museo depredador», analizado por el ICOFOM durante la Conferencia General de Milán en 2016 (ICOFOM, 2017) parece responder a enfoques nuevos y más críticos de la institución, como resultado de una museología menos fundada en valores de objetividad científica que sobre un procesos de cuestionamiento y de deconstrucción que encontramos en la nueva museología (Nouvelle muséologie) francesa y en (British New museology) la nueva museología británica (Desvallées, 1992 y 1994; Vergo, 1989). ¿Pero, para beneficio de qué tipo de registro? El carácter proselitista y hegemónico de las religiones monoté́stas parece haber contagiado al mundo de los museos que proviene de él, y podría ser criticado en este sentido. Por el contrario, es interesante observar la lógica de la convivencia que prevaleció en otros contextos, por ejemplo, dentro del Imperio Romano, donde los cultos de Mitra o Isis podían coexistir con la religión romana (Scheid, 20o8). El derrocamiento del «supremacismo museológico», como lo evoca Bruno Bru- 
lon Soares en este volumen, ¿dará paso a la coexistencia pacífica entre varios registros de interpretación de lo sagrado, o al surgimiento de otros discursos igualmente hegemónicos?

\section{Abordajes de lo sagrado en el museo}

Los autores de este número del ICOFOM StudySeries enfocan lo sagrado de variadas maneras. El tema del museo como fenómeno occidental y colonizador, mencionado anteriormente, constituye una grilla de análisis subyacente en varios artículos: la noción de lo sagrado, tal como se presenta en los museos occidentales, refleja más bien la visión de los museos sin testimoniar los muchos aspectos y dimensiones de lo sagrado mismo, tal como se experimenta en otras regiones del globo. Bruno Brulon Soares, al referirse a la museología como la expresión de una cierta fe, revela el carácter en gran medida hegemónico de esta última, sobre todo en los países occidentales. Basado en el análisis de dos exposiciones relacionadas con el museo Quai Branly, destaca los límites de la visión «científica» y estética de la museología francófona. Matías Cornejo González, basándose en el análisis del Moai HoaHakananai'a de la Isla de Pascua que se expone en el Museo Británico, cuestiona a su vez la visión supremacista occidental en gran parte artística, sobre las culturas representadas y la debilidad de las explicaciones que se ofrecen sobre las ceremonias asociadas con los objetos, haciendo de Rapa Nui una cultura viva. En tales condiciones, ¿cómo entender la esencia de estos objetos de colección a través de este tipo de mirada? La presentación de Marion Bertin sobre la organización de reservas y exposiciones en Vanuatu (distribución de reservas de acuerdo con las prohibiciones de las culturas, organización del personal a partir del conocimiento y del respeto de los saberes, organización de exposiciones temporales o permanentes), atestigua por el contrario las posibilidades de otra museología (de Oceanía) y las diferencias considerables en materia de organización práctica de los museos y los discursos resultantes. Marília Xavier Cury refiere, a partir particularmente, de varios ejemplos de Brasil, las posibilidades de colaboración entre museólogos y nativos, a fin de integrar los saberes ancestrales en el seno de los conocimientos museales: ofreciendo pistas para una posible convivencia.

Pero la relación con lo sagrado aparece también compleja para los objetos occidentales. Fanny Fouché, a través del examen del retablo cristiano, «asiento de un posible encuentro entre la inmanencia y la trascendencia», examina el carácter devocional de estas obras y su función de representación de lo invisible a través de lo visible, pero también el cambio progresivo de la devoción a la apreciación estética. «iPuede la institución museal garantizar tanto la preservación material de este tipo de objetos como la transmisión de la red heterogénea de las múltiples razones y significaciones que han hecho aparición?» se interroga Fouché. Esta pregunta resume los interrogantes de la mayoría de los autores en torno al complejo papel de la institución al enfrentar los desafíos de transmitir los saberes de civilizaciones y sociedades desaparecidas o en peligro de extinción. En un esfuerzo por paliar estas dificultades, los profesionales de 
los museos han buscado desarrollar nuevos protocolos de preservación. Caitlin Spangler-Bickell, al examinar la manera en que son usadas las categorías de inventario y conservación de altares y mausoleos en el Museo Fowler de la UCLA, muestra como el personal del museo busca preservar no solo los aspectos materiales, sino también los elementos efímeros que dan vida a estas formas sagradas, aún activas. Violette Loget e Yves Bergeron, a partir de la evolución del lugar que ocupa la religión en Quebec, analizan la situación del patrimonio religioso en esta provincia, las dificultades de financiación que enfrentan las autoridades eclesiásticas, el rol de las autoridades públicas y el de los museos. Muchas polémicas relacionadas con la voluntad del clero de enajenar un cierto número de estos bienes, aunque «fuera de comercio, intransferible e imprescriptible» por las leyes del Bajo Canadá, permite mencionar la forma en que los miembros del el clero, a veces poco interesados en la preservación de las tradiciones, participan en la dispersión de su patrimonio, y que el papel de la comunidad museal sería recordarles sus deberes en esta materia. De manera más general, Helena Wangefelt Ström presenta tres modelos que permiten analizar la diversidad del lugar de lo sagrado en el museo y sus consecuencias: los modelos detallan un espectro de posibilidades que van desde la destrucción de las identidades precedentes de un objeto hasta el beneficio desde su nueva identidad de museo, hasta la posibilidad de utilizar de múltiples maneras los objetos, permitiendo así preservar tanto su carácter vivo como inanimado.

Desde un punto de vista más institucional, Klas Grinell, a partir de un análisis de la UNESCO y sus relaciones con el ICOM, examina el poder soteriológico de los museos, considerándolos en función de la doctrina de la salvación transmitida por su discurso institucional: una salvación que puede venir por el desarrollo económico y la justicia en la tierra, la erradicación de la violencia y la pobreza. De forma paralela, Crispin Paine, cuyos aportes en torno a los vínculos entre museos y religión es conocida, analiza en su artículo la relación con lo sagrado de varias instituciones más o menos directamente relacionadas con el campo museal, evocando tanto los tesoros de iglesias y bibliotecas, como los museos que presentan teorías alternativas de la evolución (creacionismo y ciencias védicas) pero también varios parques temáticos religiosos (en Irán, India, Estados Unidos, Países Bajos o Japón) .

Tal rango de análisis no requiere necesariamente conclusiones definitivas sobre el lugar de lo sagrado en el seno del museo y la relación entre la museología y lo sagrado. A través de una frase famosa, el museólogo británico Kenneth Hudson resumió la ambivalencia de la presentación de la «realidad» en el museo: «un tigre relleno en un museo es un tigre relleno en un museo, no un tigre» (Hudson, 1977, p.7). Del mismo modo, como también señala Jan Dolak en su breve intervención, uno debe reconocer que un objeto sagrado en un museo es un objeto sagrado en un museo, y no un objeto sagrado. Su musealización no permitirá jamás, como los tigres mencionados, restaurar la misma experiencia que se puede experimentar dentro de un culto. Por otro lado, el museo, siempre y cuando pueda hacer el duelo de esta realidad vivida en otros 
lugares, constituye un espacio de cuestionamiento, debate y apertura a otras realidades que por sí solo, el templo no permite. Corresponde por lo tanto y a su turno, renunciar tanto a la tentación de imponer una visión global y autoritaria en nombre de la ciencia o la estética, pero también resistirse a la tentación de desaparecer en favor del único discurso de los otros: equilibrio precario, pero realmente propicio para el diálogo y la reflexión.

\section{Bibliografía}

Desvallées, A. (Ed.). (1992 \& I994). Vagues, une anthologie de la nouvelle muséologie, Mâcon : W \& MNES.

Duncan, A. \& Wallach, C. (1978). The Museum of Modern art as late capitalist ritual: an iconographic analysis, Marxist perspectives, 4, 28-5I.

Eliade, M. (1965). Le sacré et le profane. Paris : Gallimard.

Gregorová, A. (I980). La muséologie, science ou seulement travail pratique du musée ?, Mu Wop/ Do Tram, I, p. r9-2I.

Hudson, k. (1977). Museums for the 1980s. Paris: Unesco.

ICOFOM. (2017). The predatory Museum, ICOFOM Study Series, 45.

Lugli, A. (1998). Naturalia et Mirabilia, Les cabinets de curiosité en Europe. Paris : Adam Biro.

Mairesse, F. (2014). Le culte des musées. Bruxelles: Académie royale de Belgique (Académie en poche).

Mairesse, F. (2018). Museology and the Sacred. Materials for a Discussion. Paris: ICOFOM.

Mairesse F. (Ed.) (2019). Zbyněk Stránský et la muséologie. Une anthologie. Paris : L'Harmattan.

Mensch P. van (1992). Towards a Methodology of Museology. Zagreb: University of Zagreb, Faculty of Philosophy, Doctor's Thesis.

Otto, R. (1969). Le sacré. Paris : Payot.

Scheid, J. (2008). Pouvoir et religion à Rome. Paris : Larousse.

Texier, R. (1990). Sacré, in Jacob A. (ss la dir.) Encyclopédie philosophique universelle, II, Les notions philosophiques (pp. 229I-2293). Pari : Presses Universitaires de France.

Vergo, P. (1989). The New Museology. London: Reaktion Books. 